\title{
PARECER.
}

\section{Direito de Autor.}

\author{
Antônio Chaves \\ Catedrático de Direito Civil na Faculdade \\ de Direito da Universidade de São Paulo.
}

Reprodução proibida. Plágio. Em que consiste. Contrafação. Como se caracteriza. $O$ encontro de dois ilicitos: um caso raro de plágio-contrafação*.

\section{Consulta.}

A.P.A. publicou, pelo Instituto Brasileiro de Administração de Emprêsas, um volume de 130 páginas e que deu o título: 20 lições de Direito Fiscal.

Folheando-o displicentemente, teve um sobressalto o Prof. Ruy Barbosa Nogueira ao deparar que logo a definição de Direito Tributário não passa de mera transcrição, sem aspas, sem indicação, sem a mais leve alusão da que se encontra à pág. 26 de seu Direito Financeiro, $2 .^{a}$ ed., José Bushatsky.

Com a atenção mais espiçada, encontrou numa só página, a de n. 17, três cópias: da epígrafe Autonomia e Posição do Direito Tributário (p. 27 da sua obra citada), da definição que dá do Direito Financeiro, a p. 28, e da conceituação de ser o direito financeiro ramo autônomo de direito, com frases inteiras tiradas da p. 29, sempre sem qualquer referência ao seu trabalho.

* Por sentença de 19-8-1971, do MM. Juiz Titular da 22. ${ }^{\text {V Vara }}$ Cível da Capital, no Processo $n .^{\circ} 166 / 71$, foi determinada, realizada e não contestada a "BUSCA E APREENSÃo" do indigitado livro 20 lições de Direito Fiscal de A.P.A., objeto do presente parecer. 
E verificou que, dai por diante, cada vez mais desembaraçado, A.P.A. copia "ipsis litteris" extensos trechos da sua mencionada obra, às p. $18,19,22,23,24,26,30,33,34,67$, $68,69,71,72,73,74,75,76,77,79,81,98,99,100,101,102$, $103,104,105,106,107,109,110,111,113,114,115,116,117$, 118.

Além da cópia, são tais e tantos os plágios, que da pág. 7 à 118, descontados os espaços em branco, com os textos copiados correspondem a mais de $50 \%$ do livro "de" A.P.A.

Honra-me, em seguida à exposição, com consulta que consubstancia em dois quesitos:

1. ) Trata-se de "plágio", "cópia" e ou contrafação?

$2^{\circ}{ }^{\circ}$ Em caso positivo, cabe busca e apreensão, indenização e ou ação penal?

\section{Parecer.}

\section{Parte I.}

\section{Caracterização do ilícito.}

A contrafação, o plágio, a cópia ilegal, a transcrição, indébita, violando tanto o direito moral como o direito pecuniário de autor, estão tão claramente caracterizados, que uma ação judicial a ser eventualmente proposta dispensa até mesmo a perícia.

Quando o simples cotejo entre tão grande número de páginas e as correspondentes à obra do brilhante Catedrático de Direito Financeiro da Faculdade do Largo de São Francisco não fosse suficiente, para demonstrá-lo sob o ponto de vista material, o próprio A.P.A. se encarrega de facilitar sobremodo a tarefa do julgador.

Assim, Ruy Barbosa Nogueira ilustra, a p. 246, sua explanação com um caso que patrocinou em seu largo tirocínio forense, nos idos de 1947, dizendo, a certa altura: 
...ainda antes da reforma tributária discutimos perante o Judiciário questão semelhante, na qual o próprio contribuinte tinha reconhecido administrativamente, etc. etc."

Pois o que é que faz A.P.A.?

Singelamente, sem aspear, sem mencionar e sem invocar inclui essa página, inteirinha, entre as de ns. 109, 110, $111,112,113,114,115,116,117,118$, integralmente copiadas, com a nota intercalada a p. 117 de que na elaboração do capítulo havia sido consultada a obra de RUY BARBosa Nogueira!

Nem sequer percebeu que por essa forma inculca-se como advogado de uma causa que não podia ter patrocinado, a menos que o tivesse feito com catorze anos de idade, pois nasceu em 5-5-1933, sã vindo a formar-se aos 3-3-1958!

A doutrina reserva palavras pouco amenas para semelhante comportamento.

"A propriedade literária", - diz por exemplo PHILIP Wittenbberg, The Protection and Marketing of Literary Property, Messner, Nova Iorque, 1937, p. 65, - "como todos os bens, mercadorias e gêneros, atraem o gatuno. E tão suscetível de roubo como qualquer outra forma de propriedade: até mesmo, freqüentemente, mais ainda, devido à sua natureza intrínseca. Pode ser furtada por qualquer pessoa por uma imensa variedade de razões, inclusive vaidade, mas costumeiramente é somente onde motivos de aproveitamento se manifestam, que são tomadas providências no sentido da proteção."

O raciocínio prevalece inteiramente entre nós, em que o direito de autor é garantido como direito exclusivo de reprodução não apenas pela Constituição Federal, como também pelo Código Civil, sob a rubrica justamente $D a$ Propriedade Literária, Científica e Artística.

Zara Algardi, que escreveu mais de 800 páginas a respeito de Il Plagio Letterario e il Carattere Creativo dell'Ope$r a$, Giuffrè, Milão, 1966, consagra um inteiro capitulo an Valore delle Normativa di Correttezza, p. 149-187. 
Depois de uma ampla referência à concorrência desleal, à má fé, ao dolo, à fraude, ao erro, à culpa em suas variadas significações, focalizando as obras intelectuais demonstra a ilicitude do comportamento do plagiário quando toma subrepticiamente atitude de legítimo exercício do poder de autor:

"O procedimento levado a efeito pelo plagiário, que publique como própria obra alheia, é procedimento anormal no qual a regra de correção é violada seja frente ao autor como frente aos destinatários da obra e do cessionário do exercício do poder de publicação: semelhante violação assurge a dolo e interessa tanto à norma penal como à norma civil; através o dolo negocial o plagiário obtém o consentimento do editor à publicação da obra, representando uma falsa legitimação, concretizando a má fé num ato de representação cientemente contrário à realidade no que diz respeito aos pressupostos, com conseqüente vício do próprio ato."

\section{Contrafação.}

O ato cometido por A.P.A. é não apenas um ilícito civil, mas um verdadeiro crime, como tal catalogado pelo Código Penal de 1940, que, todavia, num excesso de síntese, engloba todas as figuras delituosas contra a propriedade intelectual, com exclusão da usurpação de nome ou pseudônimo alheio (art. 185), no art. 184, caput: violação de direito autoral, cominando detenção de três meses a um ano, ou a ridícula multa de um cruzeiro novo a cinco cruzeiros novos.

O novo Código Penal, decreto-lei 1004, de 21-10-1969, que ainda não entrou em vigor, limita-se a atualizar as multas. 
Nossa legislação anterior, apresentando o inconveniente de ser prolixa, tinha pelo menos o mérito de procurar estabelecer algumas distinções fundamentais.

Assim, dispunha o art. 19 da Lei n. 496, de 1-8-1898, reproduzido no art. $342 \S 1 .^{\circ}$ da Consolidação das Leis Penais de Vicente Piragibe, que

"Todo atentado doloso ou fraudulento contra os direitos de autor constitue crime de contrafação ..."

Mais completo o conceito que dá o Código francês, art. 425: "Toda edição de escritos, de composição musical, de desenho, de pintura ou de qualquer outra reprodução impressa ou gravada, por inteiro ou em parte, em desrespeito às leis e regulamentos relativos à propriedade dos autores, é uma contrafação, e toda contrafação é um crime."

Fazia ver Eugêne PouIllet, Traité Theorique et Pratique de la Propriété Littéraire et Artistique et du Droit de Représentation, Librairie Génerale, Paris, 3. a, ed. 1908, p. 491 que a figura delituosa representa, portanto, antes de mais nada, a violação das leis que protegem o direito exclusivo dos autores. Segue-se que pouco importa que a obra seja reproduzida sob seu nome, uma vez que isto ocorra sem as a autorização. Aquele que faz a reprodução ofereceria em vão pagar--lhe uma retribuição; nem por isto deixaria de ser contrafator, desde que não possa justificar a permissão do autor.

Alfredo Arienzo, no verbete "Contraffazione" in Novissimo Digesto Italiano, Utet, Turim, vol. IV, 1959, ,p. 461-462 ensina que o termo contrafação, ,na linguagem comum, é usado para indicar, genericamente, uma falsificação, seja como imitação fraudulenta, seja como alteração ou adulteração.

Menciona que, de acordo com uma doutrina considerada ultrapassada, os caracteres do plágio-contrafação são 
constituidos por uma quantidade notável da parte copiada ou imitada, pelo ânimo fraudulento do contrafator e, particularmente, pelo prejuízo patrimonial que daí decorre para o exercício do direito de autor.

Conclui assinalando que, na conformidade de uma mais recente e mais autorizada orientação, para acertar a existência de uma contrafação é suficiente examinar se entre as duas obras existe uma identidade que possa ser reconhecida de representação, isto é, se as duas obras constituam duas representações diferentes e originais, ou se, ao invés, seja uma representação substancialmente única.

E claro que nem toda reprodução constitui necessariamente uma contrafação.

Para que isso ocorra é necessário, ensina J. LABAuRIE, L'Usurpation en Matière Littéraire et Artistique, Boccard, Paris, 1919 , p. 48 , a concorrência de três elementos, a respeito dos quais discorre extensamente:

$1 .^{a}$ que tenha sido feita sem autorização;

$2 .^{a}$ que a obra reproduzida não tenha ainda caído no domínio da livre reprodução;

$3 .^{2}$ que constitua uma edição.

Os três elementos aparecem tão claramente reunidos na hipótese, que dispensam qualquer ulterior consideração.

Com a mesma clareza lapidar fixa esse mesmo autor as três condições pelas quais revela a reprodução seu caráter ilícito:

a) uma obra ainda protegida;

b) a falta de autorização;

c) a publicação (p. 106 e segs.),

também perfeitamente caracterizados no caso da consulta.

A lição adapta-se como uma luva ao princípio firmado no art. 669, caput, do Código Civil:

“Art. 669 - Quem publicar obra indébita, ou reproduzir obra em via de publicação ou já publicada, pertencente a outrem, sem outorga ou aquiescência deste, além de perder, em benefício 
do autor, ou proprietário, os exemplares da reprodução fraudulenta, que se apreenderem, pagar-lhe-á o valor de toda a edição, menos esses exemplares, ao preço por que estiverem à venda os genuínos ou em que forem avaliados".

Nem se diga que o fato de A.P.A. ter mencionado, de maneira capciosa, o nome do verdadeiro autor, o isente de pena e culpa.

Ainda que o tivesse proclamado desde a primeira página, com toda lealdade e sinceridade, estaria cometendo contrafação, à falta do elemento imprescindível da autorização do autor.

Demonstra-o irretorquivelmente, com uma simples interrogação, o citado EugêNe PouileEt n. 465:

"Que penserait-on d'un voleur qui crierait bien haut le nom de son volé et qui demanderait son absolution à raison de sa franchise?"

\section{Plágio.}

Complementa André Allart, Traité Theorique et Pratique de la Contrefaçon, Rousseau, Paris, 1908, p. 279 que a contrafação não reside portanto somente no fato de apresentar como sua a obra alheia: consiste ainda no fato de reproduzí-la sem a vontade do autor, seja ou não mediante a indicação do seu nome.

0 plágio é algo mais, e algo menos do que a contrafação.

E uma figura tão antiga, quão esconsa e esquiva a definições.

Tanto assim que a única lei que se aventurou a uma conceituação é a do Peru, n. 13.714, de 1-9-1961:

"Art. 124 - También infringe la Ley quien comete el delito de plagio, que consiste en difun- 
dir como propria, en todo o en parte, una obra ajena, sea textualmente ciertas alteraciones.

Tratandose de obras científicas, no se considera plagio la reproducción, aun literal, de exposiciones sistemáticas y desarrollos contenidos en obras análogas ajenas; pero a condición de citar la obra utilizada y su autor".

Mas os tratadistas, mesmo antigos, conseguiram fazê-la sair da sua toca, para analisá-la em toda sua deplorável nudez.

Assim, J. Labaurie, ao estabelecer a distinção entre plágio e contrafação, acentua, a p. 146, que, antes de mais nada, esta noção preexiste àquela.

A contrafação implica no reconhecimento e no condicionamento legal do direito de autor, '“é uma violação definida deste direito, uma ofensa regulamentada ao monopólio de aproveitamento organizado pela lei", ao passo que o plágio não resulta da lei: é anterior a ela, decorre da própria obra.

Qualifica-a como a conseqüência mais deplorável (fachêuse), mas não a menos direta da própria invenção artística, e, chegando ao ponto:

“O plágio é, ao mesmo tempo, algo mais e algo menos do que a contrafação. Porque algo mais? Porque o plagiário dá como seu, aquilo que, na realidade, não provém dele. Retira a outrem o mérito de sua criação. O contrafator, ao contrário (fazendo-se abstração da hipótese em que ele é ao mesmo tempo um plagiário, porque pode-se ser ao mesmo tempo uma e outra coisa), limita-se a reproduzir a obra alheia, ele não a assina. Ele não frustra o autor senão de um benefício pecuniário.

Porque algo menos? Porque o plágio é, de alguma maneira e do ponto de vista legal, uma 
contrafação à qual falta um dos seus elementos constitutivos."

E prossegue demonstrando que empréstimos, mesmo considerados excessivos, desde que tenham sido autorizados pelo autor da obra da qual foram retirados, não poderiram constituir uma contrafação: serão um plágio.

E por sua extensão todavia, que mais frequentemente o plágio se distingue da contrafação; é de proporções menores :

"Le plagiaire pique, de ci de là, une idée, un mot, un trait. A vrai dire, son oeuvre n'est pas véritablement la reproduction totale ou partielle d'une autre. Il emprunte plutôt qu'il ne reproduit. Que cette proposition cesse d'être exacte et le plagiat deviendra contrefaçon".

Nem a lei, nem a doutrina, nem a jurispruâência conseguiram separar rigorosamente o domínio do plágio e o da contrafação, pois a lei que reprime a contrafação não previu o plágio.

E prossegue, por outras 52 páginas, realçando a gravidade da lacuna, que poderia ser preenchida com materiais retirados na noção do direito moral, para concluir que

"O plágio é um roubo literario. Deve ser punido pela lei, e de maneira severa. . É o direito que tem o autor de se opor a que outro estenda a mão, já não sobre os proventos pecuniários que ele possa obter de sua produção, mas sobre esta mesma produção. Que toda lesão a esta prerrogativa acarrete uma pena análoga à da contrafação. E o legislador terá, ao mesmo tempo, armado os autores e os artistas contra os plagiários". 
A doutrina italiana também tem-se debruçado com particular carinho no estudo da matéria.

Eduardo Prola Caselli, Alfredo Arienzo e Franco Bile, no verbete Diritti d'Autore que escreveram para o mesmo Novissimo Digesto, v. V, p. 700, não são menos incisivos:

"Escritores e tribunais de todos os países reconhecem que existem utilizações que, no fundo, não constituem senão contrafações mascaradas ou plágios e que é necessário reprimí-las pelos menos nos casos juridicamente e praticamente mais graves, porque com elas elude-se o exercício dos direitos exclusivos, esteriliza-se substancialmente a fonte dos proveitos do autor e acrescenta-se, à ofensa patrimonial, uma ofensa até mais grave aos interesses pessoais do autor da obra".

Mas existirá um critério que permita afirmar, com segurança, a existência de plágio?

Basta examinar, esclarecem esses autores, se entre as duas obras existe uma recognoscível identidade de representaçäo, isto é, se as duas obras constituem duas diferentes representações individuais, embora de conteúdo único, ou se, ao invés, não sejam senão uma representação substancialmente única.

"Cada qual pode utilizar nos próprios trabalhos, assim o conteúdo das obras alheias, como os elementos fracionários das mesmas obras, como os fatos, os conceitos, os sentimentos, o sujeito, o sistema, o método, o estilo, a forma literária, a maneira artística, o vocabulário linguístico, etc.

Mas não é lícito, ao invés, levar a utilização até ao ponto de usurpar o conjunto dos próprios elementos, do qual irradia a individualidade da representação pessoal alheia. Quando isto acontece, e quando, pois, seja possivel reconhecer na 
nova obra, apesar das variantes, acréscimos ou reduções, a individualidade de representação de uma obra pré-existente, deve-se concluir que a obra nova é contrafação da antiga".

Zara Algard também disserta extensamente a respeito do tema, fazendo ver que, com a contrafação, o plágio caracteriza os ilícitos mais graves que possam ofender a obra e o seu autor.

Estabelece distinção entre ambas as figuras, demonstrando que a contrafação constitui um ilícito penal, o plágio um ilícito civil: somente quando se torna plágio-comtrafação sobrevém a sanção penal.

"O contrafator se apropria do resultado exterior do trabalho alheio, na sua concretização material, e utiliza-a no próprio interësse, violando o direito exclusivo patrimonial do autor.

O plagiário faz passar como própria a obra alheia (reproduzida ou elaborada). Existe contrafação somente dentro dos limites da reserva exclusiva, mas existe plágio independentemente destes limites".

Considera que tanto a expressão "apropriação" da obra, ou dos seus elementos criativos, mediante o transporte para o próprio domínio daquilo que pertence ao domínio alheio, como a "usurpação da paternidade", usadas pela doutrina e adotadas pela jurisprudência italianas, sejam em parte exatas, embora nenhuma das duas expresse de maneira completa a noção do plágio:

"...il concetto di "usurpazione" esprime in senso soggettivo la posizione del plagiario di fronte all'autore, al quale egli si sostituisce; mentre il concetto di "appropriazione" esprime in senso oggettivo il fato del trasferimento di un'opera nel dominio altrui, o, se non dell'opera nella sua in- 
tegrità, il trasferimento della sua vita creativa nella disponibilità altrui".

Prossegue demonstrando que "O plágio, considerado objetivamente, consiste na simulação de uma criação inexistente: a criação é, na realidade, uma só, aquela da obra originária, mas o plagiário, através a reprodução da obra ou da sua elaboração, ou através uma elaboração que ele mesmo executa com o seu trabalho - acrescentando ou não uma criatividade pessoal - apresenta ao público a obra como se fosse uma obra completamente nova."

Adita que, do ponto de vista subjetivo, o plágio consiste não tanto na negação da relação entre o autor e a sua obra, como na falsa afïrmação de uma relação de gênese criativa entre o plagiário e a obra.

Define então o plágio como a "simulação da originalidade da criação intelectual em obra decorrente total ou parcialmente - através o conhecimento e mediante a reprodução ou a elaboração ... - da obra, ou de elemento criativo da obra objeto de proteção de outro autor".

\section{O plágio-contrafação.}

Mas A.P.A. não se contenta em ser contrafator, não se limita a ser um mero plagiário.

Quer mais. Sua ânsia de infrator leva-o a aspirar ao título máximo. Não se satisfaz por menos do que ser ao mesmo tempo plagiário e contrafator.

À figura, acenada por J. Labaurie, dà Zara Algardi o devido relevo. Depois de consignar, a p. 199, que por "contrafação" entende-se seja a reprodução, seja qualquer outra utilização abusiva que tenha por objeto a obra, ou uma sua parte, como bem patrimonial; entendendo-se por plágio aquela usurpação que, incidindo no liame entre o autor e a sua obra, viola a paternidade intelectual, acrescenta: 
“Está claro que o plágio que acompanha a contrafação agrava-se e a qualifica, aditando à lesão de um bem patrimonial a lesão de um bem moral; e é evidente que a contrafação unida ao plágio dá à lesão moral uma consistência material, econômica, a qual, ao mesmo tempo, agrava as conseqüências de lesão moral, e cria novas graves conseqüências de caráter econômico".

Nem se diga que, por se tratar de uma obra didática, cientifica, ou pseudo-didática ou pseudo-científica, deveria o tratamento ser menos rigoroso do que com relação às obras literárias ou artísticas.

Reconhece o mesmo autor, p. 633, que para os trabalhos científicos, didáticos, de ensaio, que não têm um conteúdo original, a criatividade objeto de proteção reside antes na forma do que na substância, na expressão e não no argumento, que pode ser livremente utilizado.

Mas acrescenta logo que a simples recognocibilidade da obra, antes que a identidade da representação, constituà critério válido para a identificação do plágio: mais precisamente, a recognocibilidade de uma determinada, mesmo se disfarçada, "criatividade".

\section{A sanção.}

Pondera, a p. 641 que se a obra reproduzida ou elaborada vem a ser usurpada quanto à sua paternidade, o ilicito constitui um plágio-contrafação, que deve ser reprimido penalmente (p. 653) como lesão não somente da relação autor-obra, mas também da exclusividade do direito de autor sob o aspecto da reserva patrimonial.

Certa ou erradamente conceitua o Código Civil, já o vimos, o direto de autor como propriedade.

Quem o infringir estará, pois, cometendo roubo, furto, extorsão, violação, apropriação indébita, não merecendo 
maior benevolência do que o ladrão, o arrombador, o estelionatário, o usurpador, que, ao menos, colocam em risco a própria vida, ou a sua liberdade, enquanto que o plagiário e o contrafator contam antecipadamente com uma injustificada benevolência por parte de seus julgadores.

"La necesidad de la sancción penal" - encarecem Caros Mouchet e Sigfrido A. Radaeli, escritores que mais têm se distinguido no trato desse aspecto do problema, Los Derechos del Escritor y del Artista, Cultura Hispanica, Madrid, 1953, p. 226 - "aparece quando el hecho ilícito, además de afectar los interesses de cada persona o de un grupo social, representa un daño y un peligro público más vasto, pues son insuficientes las sancciones resultantes del ejercicio de la accion civil (ejecución forzada, resarcimiento, restitución de la cosa, nulidad del acto, etc.)".

$\mathrm{E}$ não se lhes pode desconhecer razão quando acrescentam que a violação desses direitos ocasiona conseqüências mais graves do que o mero prejuízo causado a um particular em seu patrimônio: em primeiro lugar, porque o direito intelectual contém um elemento pessoal que não existe no direito de propriedade comum, uma vez que a violação se traduz também numa ofensa à personalidade do autor; em segundo, porque, certas ofensas ao direito intelectual afetam aos interesses gerais da cultura; finalmente, porque algumas destas infrações acarretam uma lesão ao decoro e à dignidade de um país.

Já em 1908, logo na primeira página de seu clássico Traité lançava-se André Allart contra o fato de que, na prática, o crime que é a contrafação tende a diminuir em importância diante do delito civil.

"Existe menor preocupação em obter a aplicação de uma punição do que um abono de perdas e danos. Mas o que é certo é que a contrafação e as outras violações da propriedade das obras do espírito são, antes de mais nada, fatos delituosos no terreno repressivo ...

Sem dúvida para nossos espíritos habituados mais ou menos conscientemente à idéia de uma propriedade que diz 
respeito a objetos materiais, a repressão no âmbito penal das lesões a este direito tão diferente que a lei reconhece aos inventores e aos autores pode parecer excessiva. Ninguém protesta quando se coloca um ladrão atrás das grades: muitos seriam tentados fazê-lo, vendo condenar penalmente um contrafator".

E passa a demonstrar que violar a propriedade das obras de espírito é atingir não somente a propriedade, mas também a personalidade do autor:

"É tomar-lhe o que frequentemente é a obra da sua vida inteira, sua própria história, corn todo o seu séquito de lembranças, de dissabores e de esperanças. $O$ autor está todo inteiro em sua obra e é a razão por que violar uma é viclar o outro. Interesse moral, interesse material, eis aí o que representa para seu autor a obra do espírito.

Ousará alguém dizer que se possa deles fazer abstração numa legislação que protege o homem em seus bens, como em suas pessoas? Será este o momento de vir a falar do interesse nacional? $\mathrm{E}$ por outro lado beneficiar-se-á este em que uma impunidade escandalosa cubra e encoraje semelhante atos de depredação cometidos contra os inventores e os autores? Não existe ao contrário um interesse primordial em que a lealdade reine por toda parte? $O$ comércio como as artes, a indústria como o nível intelectual do país, não se ressentem da boa fé que nele domina? O que lhes ocorrerá se o inventor vê sua descoberta colocada à mercê da pilhagem, se o autor vê sua obra vilipendiada e desonrada por reproduções grosseiras que, além de seus interesses materiais, lesam aquilo que lhe é mais caro ainda, sua reputação e sua gloria? Não se chegará a desencorajar uns 
e outros, para o maior prejuízo do interesse público?

Aí estão, parece-nos, razões suficientes para justificar para a contrafação a repressão penal, porque ela é a mais enérgica de todas as sanções".

"Aprés le délit, la sanction", diz expressivamente J. LABAURIE.

Esta, pelo nosso direito, desdobra-se em sanção penal a sanção civil.

Quanto ao primeiro aspecto, já vimos que pelo art. 184 do Código Penal a detenção irá de três meses a um ano, ou multa de um a cinco cruzeiros novos.

Na mesma cominação adita o § único, incorre quem vende ou expõe à venda, adquire, oculta ou tem em depósito para a venda, obra literária, científica ou artística, produzida com violação de direito autoral.

De acordo com o art. 186 será necessária, no caso, a apresentaçâo de queixa.

Nossos repertórios, praticamente não registram precedentes de aplicação do dispositivo.

No âmbito civil são quatro as providências cabíveis:

1. Perda em benefício do autor, ou proprietário, dos exemplares da reprodução fraudulenta que se apreenderem (art. 669 do Código Civil);

2. Pagamento do valor de toda a edição, menos esses exemplares, ao preço por que estiverem à 'venda os genuínos, ou em que forem avaliados. No caso de não se conhecer o número de exemplares fraudulentamente impressos e distribuídos, será pago pelo transgressor o valor de mil exemplares, além dos apreendidos (art. 669 e seu $\S$ único), critério plausível no começo do século, não hoje; 
3. Busca e apreensão dos exemplares fraudulentamente reproduzidos (art. 672);

4. Indenização por perdas e danos, ainda que nenhum exemplar se encontre (art. 672, 2. ${ }^{\mathrm{a}}$ parte).

A págs. 549-556 de minha monografia Direito Autoral de Radiodifusão, Rev. Tribs., São Paulo, 1953, traço consideraçốes a respeito da avaliação dos prejuízos materiais e aponto a dificuldade do cálculo dos prejuízos morais.

Tais cálculos serão certamente levados a efeito por meio de perícia.

Poderá ela, eventualmente tomar como base, na consideração apenas da primeira parcela, o preço de capa do livro, calculado pela metade, se após a verificação resultar efetivamente que "apenas" $50 \%$ da obra do prof. RuY Barbosa Nogueira foi aproveitada, multiplicado pelo número hoje corrente de $\mathbf{3 . 0 0 0}$ exemplares por uma edição de livros de direito, ou a que for apurada, através de um exame de escrita da impressora, medida prevista pelo art. 5. do decreto 4.790, de 2-1-1924.

Um dos raros precedentes que poderá ser invocado em matéria de contrafação é o relatado pelo des. J. Guzzo, que se encontra à Rev. Tribs. v. 291/291.

Muito mais poderia ser expendido a respeito da matéria.

Mas o que ficou consignado será o suficiente para demonstrar a gravidade do atentado de que foi vítima o consulente, tanto maior e tanto mais ofensivo porquanto provém de um bacharel em direito.

Sinal dos tempos!

Oxalá o exemplo escarmente aqueles que se sentem tentados a palmilhar esses mesmos ínvios caminhos.

"Esperamos" com Louvet, citado por ANdré Allart, p. 6 - "que os roubos, ou melhor os latrocínios exercidos demasiado frequentemente sobre estas preciosas proprie- 
dades, não se repitam; contribuamos ao menos para fazer de modo que se reproduzam mais raramente; e contribuamos para isso com tanto maior empenho, porquanto estas fraudes, independentemente do prejuízo particular que delas resulte, não ocorrem de ordinário senão em detrimento da própria obra, em detrimento do discernimento e da instrução nacional." 